\title{
Effect of gender on the association between weight status and health-related quality of life in adolescents
}

Emilie Bonsergent ${ }^{1,2}$, Joseph Benie-Bi ${ }^{1,2}$, Cédric Baumann ${ }^{2,3}$, Nelly Agrinier ${ }^{2,3}$, Sabrina Tessier ${ }^{3,4}$, Nathalie Thilly ${ }^{1,3}$ and Serge Briançon ${ }^{1,2,3^{*}}$

\begin{abstract}
Background: Some studies have investigated the association between body mass index (BMI) and health-related quality of life (HRQoL) among adolescents, but their results have been discrepant and few paid attention to the role of gender. The present investigation aimed to assess the relationship between weight status and HRQoL in adolescents and to verify whether it was similar in boys and girls.

Methods: Five thousand two hundred and twenty six adolescents aged 14 to 18 years were included in the

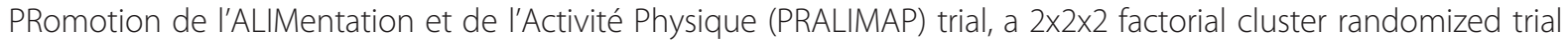
performed in 24 high schools in France. Sociodemographic, anthropometric and HRQoL data were collected. BMI was categorized in four classes (thin, normal-weight, overweight, obese). Linear regression models were used to estimate the association between weight status and HRQoL, adjusting for confounders.
\end{abstract}

Results: The mean age of adolescents was $15.7 \pm 0.6$ years and their mean BMI was $21.6 \pm 3.5 \mathrm{~kg} / \mathrm{m}^{2} ; 55 \%$ were girls. Boys were more often overweight and obese than were girls (overweight: $15.6 \%$ vs $14.2 \%$, obese: $4.8 \%$ vs $3.3 \%$ ), and girls were more likely to be thin (5.5\% vs $4.5 \%, p=0.0042)$. All HRQoL scores were higher for boys $(p=<0.0001)$. Weight status was not associated with physical and social scores neither in boys nor in girls. Conversely, it was associated with mental score, but differently in girls than boys. As compared with normal-weight girls, thin girls had better mental HRQoL ( $\beta=+6.17, p=0.0010)$, and overweight and obese girls had lower mental HRQoL $(\beta=-3.89$ and $\beta=-5.90$, respectively, $p<0.001$ ). Mental HRQoL was lower for thin, overweight and obese boys than for normal-weight boys $(\beta=-4.97, \beta=-1.68$ and $\beta=-3.17$, respectively, $p<0.0001$ ).

Conclusions: Gender can modify the association between weight status and HRQoL in adolescents. Body image could be an important target of public health programs to improve subjective health during adolescence.

Keywords: Health-related quality of life, Weight status, Adolescents, High school

\section{Background}

Obesity is a worldwide problem affecting an increasing number of people in all age groups, particularly children and adolescents [1], with differences in prevalence between boys and girls [2,3]. In France, the prevalence of overweight and obesity, classified according to the International Obesity Task Force [4], increased from 10.8\%

\footnotetext{
* Correspondence: serge.briancon@univ-lorraine.fr

${ }^{1}$ University of Lorraine, Paris Descartes University, EA4360, Apemac, Nancy, France

${ }^{2}$ University of Lorraine, Faculty of Medicine, School of Public Health, Nancy, France

Full list of author information is available at the end of the article
}

(overweight: $8.4 \%$, obesity: $2.4 \%$ ) to $15.7 \%$ (overweight: 12.4\%, obesity: $3.3 \%$ ) between 1990 and 2004 in adolescents aged 14 to 15 years [5]. A national study of nutrition and health reported a prevalence of overweight and obesity of $16.7 \%$ (overweight: $12.4 \%$, obesity: $4.3 \%$ ) in 2006 among adolescents aged 15 to 17 years [6].

Overweight and obesity can affect adolescent health, and metabolic and physiological changes associated with overweight and obesity in adolescence continue into adulthood and increase the risk of morbidity (e.g., coronary heart disease, diabetes mellitus and atherosclerosis) and mortality [7-11]. However, the consequences are not

\section{Biomed Central}


limited to physical health, as psychological and social aspects of well-being may also be affected [12].

Health-related quality of life (HRQoL) is a multidimensional concept that can be defined as an individual's satisfaction or happiness in various life domains that affect or are affected by health [13-15]. During recent decades, HRQoL has become an important outcome to measure when assessing the effects of numerous disorders, short- and long-term disabilities, and diseases in different populations, and can help guide policies or interventions to improve health. Moreover, being overweight or obese in adolescence can affect future HRQoL [16]. Thus, improving HRQoL has become the primary justification for many interventions, medications, behavioural counselling programs, and other therapies $[16,17]$. Some studies suggest that there are differences in HRQoL between boys and girls during adolescence, with girls scoring lower than boys [18-20]. Previous studies in adolescents have also shown that overweight and obesity impair HRQoL [21-26], but the results have been discrepant. Some studies reported the greatest impairment in the physical and social dimensions of HRQoL [25], whereas others reported impairment in the emotional or mental dimensions $[23,26]$.

The discrepant results may be explained by heterogeneous target populations (more often clinical- than community-based), and differences in study design and outcome measures (use of country-specific centile charts to define weight status and different HRQoL instruments) [25]. Although important associations were frequently found in clinical samples, such samples are often subject to selection bias (e.g. clinical samples more often present serious health conditions and lower HRQoL scores than do general population samples). Few studies have targeted the general population despite the potential interest in terms of the external validity of the results [25]. In addition, few studies investigated and showed differences between boys and girls in community samples; these studies also excluded thin adolescents [25] and only one looked at the possible modifying effect of gender on the association between body mass index (BMI) and HRQoL [26]. In fact, because thinness represents the ideal body image, mainly for females, the impact of weight status on HRQoL could differ between genders [27].

The present investigation aimed to assess the association between weight status and HRQoL in adolescents and to verify whether it was similar in boys and girls. The hypothesis that weight status influences HRQoL differently in boys and girls was tested.

\section{Methods}

\section{Design}

The present investigation was performed using a sample of 5,226 high school adolescents aged 14 to 18 years recruited for the PRALIMAP (PRomotion de l'ALIMentation et de l'Activité Physique) trial [28]. Body size and HRQoL data collected at inclusion in this trial were used. PRALIMAP was a $2 \times 2 \times 2$ factorial cluster randomized trial assessing the effectiveness of three interventional strategies for overweight prevention (education, the environment, and overweight screening and care management) in 24 state-run high schools in France over 2 years. Data were collected at three visits: start of grades 10 (T0), 11 (T1) and 12 (T2). Adolescents were given written and oral information in the high school, and an information letter was sent to their parents. Adolescents whose parent(s) refused in writing did not contribute to data collection.

The trial was approved by the French ethics committee "Commission Nationale de l'Informatique et des Libertés" ( $\left.{ }^{\circ} 906312\right)$, and registered in clinicaltrials. gov (no. NCT00814554; http://clinicaltrials.gov/ct2/ show/NCT00814554).

\section{Data collection}

Socio demographic, anthropometric and HRQoL data were collected at PRALIMAP inclusion in grade 10 (T0). Data on socio demographic characteristics and HRQoL were collected by self-administered questionnaires completed in the classroom. Additional socio demographic characteristics were obtained from the Board of Education database. Anthropometric measurements were performed by trained high school nurses.

\section{Socio demographic data}

Data were collected on age, gender, type of high school (general and technological or vocational), social and professional class of the family head (according to the definition of the national institute of statistical and economic studies in France [29]), parent occupation (how many parents work), adolescent perceptions of parental weight status (overweight or not) and family income (high, moderate or low). Age was classified in three groups according to the average age of adolescents registered for grade 10 in France (15 years): < 15 years, 15 years, $>15$ years.

\section{Weight status}

Body weight and height were measured twice in a single session. Body weight of adolescents wearing underwear was measured to an accuracy of $0.05 \mathrm{~kg}$ using a calibrated electronic scale $\left(\right.$ SECA $^{\circledR}$ : model number 873 1321009). Height was measured to the nearest $0.1 \mathrm{~cm}$, without shoes, using a stadiometer $\left(\mathrm{SECA}^{\circledR}\right.$ : reference SECA 214 SEC 01). BMI was calculated as weight/ height ${ }^{2}$ from the means of the two measurements. The International Obesity Task Force (IOTF) and the Cole age- and sex-specific cut-off values for BMI were used 
to define four BMI classes: thin [30], normal, overweight and obese [4].

\section{HRQoL}

HRQoL was assessed using the Duke Health Profile for adolescents [31,32], a 17-item, generic, self-reporting questionnaire validated in the French language [32,33]. Among the 10 dimensions explored in this questionnaire, the physical, mental and social dimensions (five items each) are of most interest because they correspond to the World Health Organization (WHO) definition of health [34]; their scores are estimated independently on a 0-100 scale, with higher scores indicating better HRQoL.

\section{Statistical analysis}

Continuous variables are described as means \pm standard deviation (SD), and categorical variables as percentages. Because of the cluster design of the trial (cluster=high school), the intra-cluster similarity of HRQoL scores was estimated using the intraclass correlation coefficient (ICC) [28]. As the ICC was low (between 0.005 and 0.052), non-hierarchical analysis was used [35]. The comparisons between boys and girls were made using the Student $t$ test for continuous variables, and the chisquare test for categorical variables. The interaction between gender and weight status was tested for all HRQoL dimensions. A deviation from linearity between BMI as a continuous and ordinal variable and HRQoL scores was observed $(\mathrm{p}<0.05)$ Thus BMI was considered as a nominal variable. Bivariate and multivariate analyses of variance models were conducted to estimate the association between weight status and HRQoL scores with HRQoL as the continuous dependent variable and weight status as a categorical main independent variable.

All statistical analyses involved use of SAS 9.2 (SAS Inst., Cary, NC, USA); $<<0.05$ was considered statistically significant.

\section{Results}

\section{Sample characteristics}

Characteristics of the 5,226 adolescents are shown in Table 1 . The mean age was $15.7 \pm 0.6$ years, and $55 \%$ were girls $(n=2,872)$. Both parents of $64.9 \%(n=3,355)$ were working, and in $48.0 \%(n=2,467)$ the family head was an employee or worker. Most adolescents attended general and technological high school (83.2\%, $\mathrm{n}=4,450)$. More than half reported a high family income level $(n=3,017)$ and $40.2 \%$ considered their parents overweight $(\mathrm{n}=2,072)$.

As compared with girls, boys were older $(\mathrm{p}=0.0004)$, more often attended a vocational high school $(\mathrm{p}<0.0001)$, less often considered their parents as overweight $(\mathrm{p}=0.0023)$ and were more likely to have two parents working $(\mathrm{p}=0.0100)$ (Table 1).

\section{Weight status and HRQoL}

The mean BMI was $21.6 \pm 3.5 \mathrm{~kg} / \mathrm{m}^{2}$ and did not differ significantly between genders (Table 1 ). The prevalence of overweight and obesity was higher for boys than girls (overweight: $15.6 \%$ vs $14.2 \%$, obese: $4.8 \%$ vs $3.3 \%$ ), whereas the proportion of those being thin was higher among girls than boys (5.5\% vs $4.5 \%)(\mathrm{p}=0.0042)$. Physical HRQoL scores were higher than social and mental scores. Boys had significantly higher HRQoL scores than girls, whatever the dimension (all $\mathrm{p}<0.0001$, Table 1 ).

\section{Effect of gender on the association between weight status and HRQoL}

For both boys and girls, the higher the age, the lower the HRQoL scores. Moreover, the less favourable the socio demographic parameters (social and professional class, parental occupation, perception of family income and of parental weight status), the lower the HRQoL scores (Tables 2 and 3).

On multivariate analysis, weight status was associated with mental HRQoL but not with physical and social HRQoL scores for boys and girls (Tables 2 and 3). A significant interaction between gender and weight status $(\mathrm{p}<0.0001)$ was found; the higher the BMI, the lower the mental HRQoL score in girls, but not in boys (Figure 1). As compared with normal-weight girls, thin girls had a higher mental HRQoL score $(\beta=+6.17, \mathrm{p}=0.001)$, whereas overweight and obese girls had a lower mental HRQoL score $(\beta=-3.89, p=0.016$ and $\beta=-5.90, p=0.0374$ respectively). In contrast, thin, overweight and obese boys had a lower mental HRQoL score than normalweight boys $(\beta=-4.97, \beta=-1.68$ and $\beta=-3.17$ respectively, $\mathrm{p}=0.0221$ ).

\section{Discussion}

Gender moderated the association between weight status and mental HRQoL score. Among girls, mental HRQoL was higher for thin girls and decreased with increasing BMI. In contrast, mental HRQoL was lower for thin, overweight and obese rather than normal-weight boys.

Only one study investigated the effect of gender on the association between weight status and HRQoL in a community sample including older adolescents (14-18 years old) [26] who are affected by physical and psychological changes due to puberty. Keating et al. showed that girls who were overweight and obese had significantly lower physical functioning scores than normal-weight girls, but the same was not true for boys. Similarly, girls who were obese had significantly lower school and emotional functioning scores than did normal-weight girls, but the same was not true in boys. Keating et al. excluded thin adolescents, included younger and older adolescents (1118 years), and used the PedsQL to estimate HRQoL scores. In our study, thin adolescents were not excluded, 
Table 1 Sociodemographic characteristics weight status and health related quality of life (HRQoL) scores in adolescents in PRALIMAP

\begin{tabular}{|c|c|c|c|c|c|c|c|}
\hline & \multicolumn{2}{|l|}{$\begin{array}{l}\text { All } \\
N=5,226\end{array}$} & \multicolumn{2}{|c|}{$\begin{array}{l}\text { Boys } \\
N=2,354(45.0 \%)\end{array}$} & \multicolumn{2}{|c|}{$\begin{array}{l}\text { Girls } \\
\mathrm{N}=2,354(45.0 \%)\end{array}$} & \multirow[t]{2}{*}{ p-value } \\
\hline & Mean/\% & SD & Mean/\% & SD & Mean/\% & SD & \\
\hline \multicolumn{8}{|l|}{ Socio demographics Characteristics } \\
\hline Age (years) & 15.7 & 0.6 & 15.7 & 07 & 15.6 & 0.6 & 0.0004 \\
\hline Age groups & & & & & & & $<0.0001$ \\
\hline 15 years old & 68.0 & & 64.8 & & 70.5 & & \\
\hline$<15$ years old & 2.4 & & 2.4 & & 2.5 & & \\
\hline$>15$ years old & 29.6 & & 32.7 & & 27.0 & & \\
\hline Type of high school & & & & & & & $<0.0001$ \\
\hline General/technological & 83.2 & & 78.2 & & 87.2 & & \\
\hline Vocational & 16.8 & & 21.8 & & 12.8 & & \\
\hline Social and professionals class of family head & & & & & & & 0.0995 \\
\hline Farmers, store keeper, craftsmen, managers & 8.2 & & 7.7 & & 8.6 & & \\
\hline Executives & 14.3 & & 15.2 & & 13.5 & & \\
\hline Intermediate jobs & 20.2 & & 20.5 & & 19.9 & & \\
\hline Employees jobs & 48.0 & & 48.1 & & 47.9 & & \\
\hline Unemployed, retired & 9.4 & & 8.5 & & 10.2 & & \\
\hline Parent occupation & & & & & & & 0.0100 \\
\hline Both parents work & 64.9 & & 66.1 & & 63.9 & & \\
\hline One parent has a job & 29.6 & & 29.5 & & 29.8 & & \\
\hline Neither parent work & 5.4 & & 4.4 & & 6.3 & & \\
\hline Perception of family income & & & & & & & 0.7371 \\
\hline Low & 6.4 & & 6.2 & & 6.6 & & \\
\hline Moderate & 34.2 & & 34.7 & & 33.9 & & \\
\hline High & 59.3 & & 59.1 & & 59.5 & & \\
\hline Parents considered overweight by adolescent & 40.2 & & 37.9 & & 42.1 & & 0.0023 \\
\hline \multicolumn{8}{|l|}{ Weight status } \\
\hline Body mass index $\left(\mathrm{kg} / \mathrm{m}^{2}\right)$ & 21.6 & 3.5 & 21.5 & 3.5 & 21.6 & 3.5 & 0.1639 \\
\hline Body mass index class & & & & & & & 0.0042 \\
\hline Thin & 5.0 & & 4.5 & & 5.5 & & \\
\hline Normal & 76.1 & & 75.1 & & 77.0 & & \\
\hline Overweight & 14.9 & & 15.6 & & 14.2 & & \\
\hline Obese & 4.0 & & 4.8 & & 3.3 & & \\
\hline \multicolumn{8}{|l|}{ HRQoL scores (0-100) } \\
\hline Mental score & 64.5 & 23.3 & 73.3 & 20.0 & 57.3 & 23.3 & $<0.0001$ \\
\hline Physical score & 75.6 & 18.5 & 82.2 & 15.7 & 70.1 & 18.8 & $<0.0001$ \\
\hline Social score & 68.8 & 19.1 & 71.9 & 18.7 & 66.2 & 19.1 & $<0.0001$ \\
\hline
\end{tabular}

a: Chi-square test for qualitative variables; Student test for qualitative variables; b: according to the international Obesity Task Force.

only older adolescents were included (14-18 years), and the adolescent Duke Health Profile was used. Like Keating et al., the present investigation showed that overweight and obese girls had poorer mental HRQoL score than did normal-weight girls. However, weight status (including thin) and mental HRQoL score were linearly and negatively related in girls but in not boys, thin girls having a better mental HRQoL score than normal-weight girls. Thus, it appears important to include thin adolescents when investigating weight status.

Our results suggest that the perception of ideal body size and shape differs between adolescent girls and boys; 
Table 2 Bivariate and multivariate analysis of the association between weight status and HRQoL in boys ( $N=2,354)$

\begin{tabular}{|c|c|c|c|c|c|c|c|c|c|c|c|c|}
\hline \multirow[t]{3}{*}{ Variables } & \multicolumn{4}{|c|}{ Mental HRQoL } & \multicolumn{4}{|c|}{ Physical HRQoL } & \multicolumn{4}{|c|}{ Social HRQoL } \\
\hline & \multicolumn{2}{|c|}{ Bivariate } & \multicolumn{2}{|c|}{ Multivariate } & \multicolumn{2}{|c|}{ Bivariate } & \multicolumn{2}{|c|}{ Multivariate } & \multicolumn{2}{|c|}{ Bivariete } & \multicolumn{2}{|c|}{ Multivariate } \\
\hline & $\beta$ & SE & $\beta$ & SE & $\beta$ & SE & $\beta$ & SE & $\beta$ & SE & $\beta$ & SE \\
\hline \multicolumn{13}{|l|}{ Weight status" (vs normal) } \\
\hline Thin & -4.72 & 2.01 & $-4.91^{*}$ & 2.02 & -1.85 & 1.57 & $-2.33^{\mathrm{NS}}$ & 1.60 & -3.96 & 1.88 & $-3.79^{\mathrm{NS}}$ & 1.89 \\
\hline Overweight & -2.51 & 1.14 & -1.79 & 1.16 & -0.92 & 0.90 & -0.49 & 0.91 & -1.17 & 1.07 & -0.81 & 1.08 \\
\hline Obese & -5.04 & 1.93 & -3.63 & 1.97 & -1.84 & 1.51 & -0.46 & 1.56 & -3.10 & 1.80 & -2.80 & 1.84 \\
\hline \multicolumn{13}{|l|}{ Sociodemographic characteristic } \\
\hline $\begin{array}{l}\text { Vocational high school (vs general and } \\
\text { technological school) }\end{array}$ & -1.28 & 1.02 & $-0.16^{\mathrm{NS}}$ & 1.12 & -1.47 & 0.80 & $-0.24^{N S}$ & 0.88 & -0.44 & 0.95 & $0.36^{\mathrm{NS}}$ & 1.05 \\
\hline \multicolumn{13}{|l|}{ Age groups (vs 15 years old) } \\
\hline$<15$ years old & -0.19 & 2.68 & $0.80^{* * *}$ & 2.68 & 1.18 & 2.10 & $1.37^{* * *}$ & 2.12 & -1.36 & 2.52 & $-1.36^{\mathrm{NS}}$ & 2.50 \\
\hline$>15$ years old & -5.04 & 0.88 & -4.77 & 0.96 & -3.68 & 0.69 & -3.42 & 0.76 & -2.37 & 0.82 & -2.02 & 0.90 \\
\hline \multicolumn{13}{|c|}{ Social and professional class of family head (vs executives) } \\
\hline Farmers, storekeepers, craftsmen, managers & 1.85 & 1.85 & $2.43^{\mathrm{NS}}$ & 1.85 & 0.24 & 1.44 & $1.03^{\mathrm{NS}}$ & 1.46 & 0.90 & 0.71 & 1.62 & 1.73 \\
\hline Intermediate jobs & -1.21 & 1.41 & -0.42 & 1.41 & -1.40 & 1.10 & -0.60 & 1.12 & 0.52 & 1.31 & 0.98 & 1.32 \\
\hline Employees, workers & -0.85 & 1.23 & 1.22 & 1.27 & -1.85 & 0.96 & -0.25 & 1.00 & 0.84 & 1.14 & 2.37 & 1.18 \\
\hline Unemployed retired & -2.66 & 1.79 & 0.71 & 2.02 & -3.19 & 1.40 & -0.69 & 1.59 & -4.49 & 1.66 & -1.96 & 1.88 \\
\hline \multicolumn{13}{|l|}{ Parent occupation (vs both parents work) } \\
\hline One parent has a job & -1.62 & 0.92 & $0.11^{\mathrm{NS}}$ & 0.96 & -1.31 & 0.72 & $-0.28^{\mathrm{NS}}$ & 0.76 & -2.23 & 0.86 & $-0.81^{\text {NS }}$ & 0.90 \\
\hline Neither parent works & -2.20 & 2.04 & 1.28 & 2.41 & -1.53 & 1.60 & 1.23 & 1.90 & -2.66 & 1.92 & 2.59 & 2.26 \\
\hline \multicolumn{13}{|c|}{ Perception of family income (vs perception of high income) } \\
\hline Moderate & -3.64 & 0.89 & $-3.15^{* * *}$ & 0.91 & -3.13 & 0.70 & $-2.76^{* *}$ & 0.72 & -4.01 & 0.82 & -3.83 & 0.85 \\
\hline Low & -11.99 & 1.75 & -11.12 & 1.82 & -3.87 & 1.37 & -3.31 & 1.44 & -11.09 & 1.62 & -10.5 & 1.70 \\
\hline Parents considered overweight (yes vs no) & -5.72 & 0.85 & $-4.97^{* * *}$ & 0.87 & -3.10 & 0.67 & $-2.80^{* * *}$ & 0.69 & -2.83 & 0.80 & $-2.19^{*}$ & 081 \\
\hline
\end{tabular}

\# International Obesity Task Force body mass index classes; NS: no significant; ${ }^{*} p<0.05 ;{ }^{* *} p<0.001 ;{ }^{* * *} p<0.0001 ;$ SE: standard error.

thinness represented the ideal body image for girls, which could explain the better mental HRQoL score in thin girls [27]. The representation of the ideal body shape may come from a collective vision influenced by television, magazines, advertisements and the social stigma attached to obesity and the "fat phobia" that pervades our daily life. Girls seek to be thin and fit, not only to be healthy but also to be perceived by themselves and others as having desirable personal qualities. Girls may be more attuned to or aware of their bodies and their health than boys. Girls consistently report greater body dissatisfaction than do boys [36,37]. Some studies showed that girls were more likely to perceive themselves as being overweight than boys [36,38-40]. In a study by Lawler et al. [41], all overweight girls revealed a desire to weigh less, as compared with only $78.6 \%$ of overweight boys. Average-weight girls wanted to be lighter, whereas average-weight boys were satisfied with their bodies or wanted to be bigger [41]. Boys find a greater variety of body shapes socially acceptable compared to girls, and girls have a narrower range of what is considered the ideal body image [42]. Even if some men strive to lose weight to conform to today's ideal body shape, the ideal image for most boys is muscular and strong, the main characteristics of virility, so boys with an athletic build may be more popular among their peers and more difficult to victimize [43]. This observation may explain the non-linear association between BMI and HRQoL observed in boys.

Cross-sectional community surveys reflect the subjects' HRQoL at one time, which means that temporality cannot be established [44] and it remains unclear whether BMI determines HRQoL or vice versa. Some studies merged data for adolescents and younger children [25], but findings in children cannot be extrapolated to adolescents. Adolescence is the period of transition to adulthood and sexual differentiation. This stage presents several characteristics that justify a particular interest in terms of obesity, as well as at the level of prevention, screening and care. Indeed, obese adolescents are more likely than their normal-weight counterparts to remain obese into adulthood ( $78 \%$ for men vs. $63 \%$ for women) [45]. Moreover, the large sample size gave the study considerable statistical power. In addition, 
Table 3 Bivariate and multivariate analysis of the association between weight status and HRQoL in girls $(\mathrm{N}=2,872)$

\begin{tabular}{|c|c|c|c|c|c|c|c|c|c|c|c|c|}
\hline \multirow[t]{3}{*}{ Variables } & \multicolumn{4}{|c|}{ Mental HRQoL } & \multicolumn{4}{|c|}{ Physical HRQoL } & \multicolumn{4}{|c|}{ Social HRQoL } \\
\hline & \multicolumn{2}{|c|}{ Bivariate } & \multicolumn{2}{|c|}{ Multivariate } & \multicolumn{2}{|c|}{ Bivariate } & \multicolumn{2}{|c|}{ Multivariate } & \multicolumn{2}{|c|}{ Bivariete } & \multicolumn{2}{|c|}{ Multivariate } \\
\hline & $\beta$ & SE & $\beta$ & SE & $\beta$ & SE & $\beta$ & SE & $\beta$ & SE & $\beta$ & SE \\
\hline \multicolumn{13}{|l|}{ Weight status" (vs normal) } \\
\hline Thin & 6.93 & 1.90 & $6.46^{* * *}$ & 1.91 & 2.47 & 1.55 & $2.16^{\mathrm{NS}}$ & 1.57 & -0.19 & 1.57 & $0.43^{N S}$ & 1.57 \\
\hline Overweight & -4.86 & 1.24 & -3.45 & 1.24 & -0.85 & 1.01 & 0.41 & 1.02 & -2.58 & 1.03 & -1.94 & 1.02 \\
\hline Obese & -8.49 & 2.43 & -5.24 & 2.47 & -3.33 & 1.98 & -0.78 & 2.02 & -2.70 & 2.02 & 0.88 & 2.04 \\
\hline \multicolumn{13}{|l|}{ Sociodemographic characteristic } \\
\hline $\begin{array}{l}\text { Vocational high school (vs general and } \\
\text { technological school) }\end{array}$ & -4.88 & 1.43 & $-1.85^{\text {NS }}$ & 1.55 & -4.30 & 1.16 & $-3,49^{N S}$ & 0,72 & -5.76 & 1.18 & $-3.28^{*}$ & 1.27 \\
\hline \multicolumn{13}{|l|}{ Age groups (vs 15 years old) } \\
\hline$<15$ years old & 1.53 & 2.78 & 2.17 & 2.74 & 0.58 & 2.25 & $0.94^{* * *}$ & 2.24 & -2.65 & 2.27 & $-3.04^{* * *}$ & 2.25 \\
\hline$>15$ years old & -7.10 & 0.97 & -6.35 & 1.03 & -4.48 & 0.79 & -3.91 & 0.85 & -5.34 & 0.80 & -3.76 & 0.85 \\
\hline \multicolumn{13}{|c|}{ Social and professional class of family head (vs executives) } \\
\hline Farmers, storekeepers, craftsmen, managers & -1.70 & 1.91 & $0.44^{N S}$ & 1.87 & 0.44 & 1.54 & $1.52^{\mathrm{NS}}$ & 1.53 & -1.81 & 1.56 & $0.08^{* * *}$ & 1.54 \\
\hline Intermediate jobs & -2.95 & 1.54 & -0.36 & 1.52 & -1.94 & 1.24 & 0.03 & 1.24 & -1.44 & 1.26 & 0.31 & 1.25 \\
\hline Employees, workers & -3.97 & 1.35 & 0.35 & 1.36 & -0.87 & 1.09 & 1.86 & 1.11 & -2.49 & 1.10 & 0.80 & 1.12 \\
\hline Unemployed retired & -2.76 & 1.82 & 3.68 & 2.08 & -3.17 & 1.46 & 1.34 & 1.71 & -4.30 & 1.49 & 1.83 & 1.72 \\
\hline \multicolumn{13}{|l|}{ Parent occupation (vs both parents work) } \\
\hline One parent has a job & -2.75 & 0.97 & $-0.89^{\text {NS }}$ & 0.99 & -2.11 & 0.78 & $-0.79^{\mathrm{NS}}$ & 0.82 & -2.80 & 0.79 & $-1.12^{* * *}$ & 0.82 \\
\hline Neither parent works & -2.36 & 1.82 & 0.00 & 2.16 & -1.68 & 1.48 & 1.37 & 1.77 & -4.61 & 1.50 & -1.11 & 1.78 \\
\hline \multicolumn{13}{|c|}{ Perception of family income (vs perception of high income) } \\
\hline Moderate & -6.19 & 0.93 & $-5.75^{* * *}$ & 0.94 & -4.95 & 0.75 & $-4.54^{* * *}$ & 0.77 & -6.57 & 0.76 & $-6.20^{* * *}$ & 0.77 \\
\hline Low & 16.57 & 1.76 & -15.42 & 1.83 & -10.57 & 1.44 & -9.52 & 1.50 & -13.61 & 1.44 & -12.56 & 1.51 \\
\hline Parents considered overweight (yes vs no) & -5.33 & 0.88 & $-3.72^{* * *}$ & 0.88 & -4.62 & 0.71 & $-3.49^{* * *}$ & 0.72 & -3.69 & 0.72 & $-2.46^{* *}$ & 0.73 \\
\hline
\end{tabular}

\#International obesity task force body mass index classes; NS: no significant ${ }^{*} p<0,05 ;{ }^{* *} p<0,001 ;{ }^{* *} p<0,0001$.

SE: standard error.

the quality of anthropometric measurements reported by qualified and trained nurses in our study attested to the validity of the data and minimized biased measurements. As linearity was not verified, BMI was considered as o nominal variable with four classes including thinness. Therefore, HRQoL score was estimated for thinness, and strongly differed between girls and boys.

\section{Implications for research and public health}

The association between weight status and HRQoL in adolescents must be studied by gender and the results taken into account when developing health programs, in order to identify the best strategy with which to address these issues. The present investigation found that girls had significantly lower mental HRQoL than did boys and their decrease in HRQoL was higher when their body size increased. This information could help educators implementing health programs that focus on the educational system and are tailor-made to meet the specific needs of target groups. Finally, thinness in boys affected HRQoL in the same way as overweight and obesity in boys. Thinness may be an issue to consider in public health programs for adolescents.

\section{Conclusions}

Gender moderates the association between weight status and HRQoL mental dimension among adolescents in the PRALIMAP trial, with a linear decrease in girls and a non-linear decrease in boys. Body image could be an important target of interventions to improve subjective health in adolescence. The present study contributes to the knowledge of adolescent HRQoL by providing a better understanding of gender-specific factors associated with body image and highlighting the principal role of weight status in HRQoL for both boys and girls. Targeting educational interventions to adolescents could be helpful in reducing the increasing prevalence of obesity and the effect of overweight on mental HRQoL. Public health programs must take this into account in order to adapt their message to adolescents. Longitudinal studies would be helpful in order to establish the 


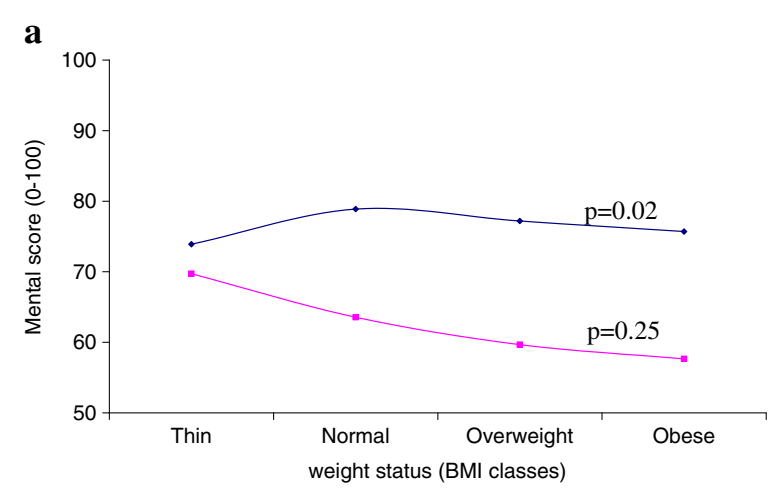

b

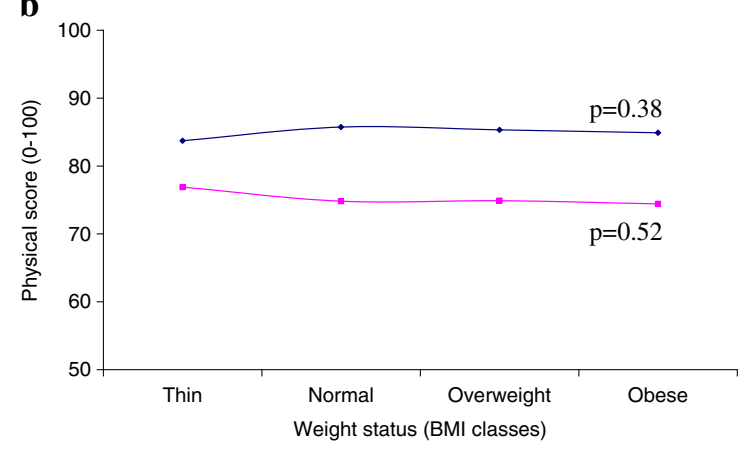

c

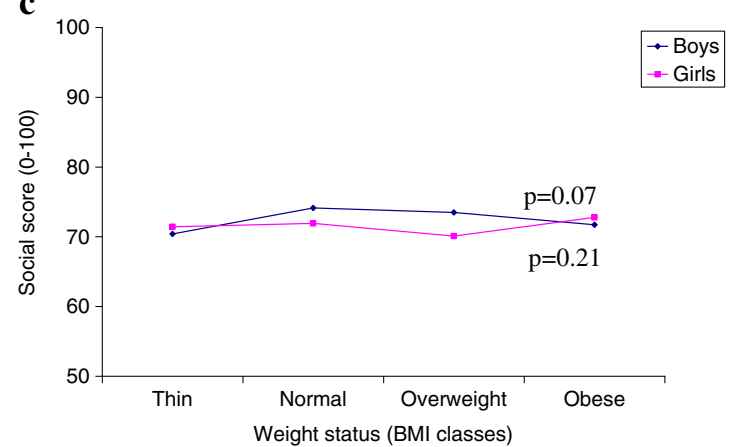

Figure 1 Trends of mental (a), physical (b) and social (c) HRQoL scores according to weight status. Note: Weight status is in BMl classes. Trends of HRQOL scores are adjusted for confounders. BMI classes are defined according to the International Obesity TaskForce (IOTF) classification; p: p-value of the linearity test of weight status on HRQoL scores (if $p$-value $<0.05$ then the linearity was not verified).

causality of the association between BMI and HRQoL in adolescents.

\section{Abbreviations}

BMI: Body Mass Index; HRQoL: Health-Related Quality of Life; ICC: Intra-class Correlation Coefficient; IOTF: International Obesity TaskForce; PedsQL: Pediatric Quality of Life inventory; PRALIMAP: PRomotion de I'ALIMentation et de I'ACtivité Physique; WHO: World Health Organization.

\section{Competing interests}

The authors declare that they have no competing interests.

\section{Authors' contributions}

All the authors actively participated in the collaborative work leading to the publication. NA, EB, JB, CB, SB, ST and NT are outcomes evaluation and statistical managers. EB, JB, CB and SB drafted the manuscript. All the authors read and approved the final manuscript. $E B$ is the paper guarantor.

\section{Acknowledgments}

The PRALIMAP trial group acknowledges the adolescents and their parents who participated in the study and the high school professionals (nurses, teachers, administrative staff, headmasters and catering staff) who helped recruit adolescents and deliver the interventions.

We thank Stéphane Thomas and the statistical team of the Nancy-Metz Academy Board of Education for making available the required student database. We also thank Edith Lecomte and Cécile Gailliard of the national conservatory of arts and crafts (CNAM), Evelyne Aptel and Rozenn De Lavenne of the local school office of the Nancy-Metz academy and Lucette Barthélémy and Aline Osbery of the regional institute for health education (IREPS).

We thank all the administrative and technical staff of CNAM, the Nancy School of Public Health, the Nancy-University EA 4360 Apemac team and the epidemiology and clinical evaluation department of Nancy-University Hospital for their contribution to data collection, data entry and management, activity reporting, and logistic and financial management. The PRALIMAP trial received support from public and private sectors. Special acknowledgements are addressed to ARH Lorraine, Conseil Régional de Lorraine, DRASS de Lorraine, GRSP de Lorraine, Fondation Cœurs et Artères, Fondation Wyeth, Ministère de l'enseignement supérieur et de la recherche, Inca, IRESP, Régime local d'assurance maladie d'Alsace Lorraine and Urcam de Lorraine. All trial steps, design, data collection and analysis, write-up, and reports are and will be performed independently of any funding or sponsoring agency.

\section{Author details}

${ }^{1}$ University of Lorraine, Paris Descartes University, EA4360, Apemac, Nancy, France. ${ }^{2}$ University of Lorraine, Faculty of Medicine, School of Public Health, Nancy, France. ${ }^{3}$ Nancy University Hospital, Department of Clinical Epidemiology and Evaluation, Nancy, France. ${ }^{4}$ UMR U557 INSERM/U1125 Inra/CNAM/Paris 13, SBMH-Paris 13 University, Bobigny, France.

Received: 7 June 2012 Accepted: 28 September 2012

Published: 18 November 2012

\section{References}

1. Lobstein T, Baur L, Uauy R: Obesity in children and young people: a crisis in public health. Obes Rev 2004, 5(Suppl 1):4-104.

2. Kirchengast S: Gender Differences in Body Composition from Childhood to Old Age: An Evolutionary Point of View. J Life Sci 2010, 2:1-10.

3. Ogden CL, Carroll MD, Kit BK, Flegal KM: Prevalence of obesity and trends in body mass index among US children and adolescents, 1999-2010. JAMA 2012, 307:483-490.

4. Cole TJ, Bellizzi MC, Flegal KM, Dietz WH: Establishing a standard definition for child overweight and obesity worldwide: international survey. BMJ 2000, 320:1240-1243.

5. De Peretti C, Castetbon K: Surpoids et obésité chez les adolescents scolarisés en classe de troisième. Études et résultats 2004, 283:1-4.

6. Programme National Nutrition Santé (PNNS): Colloque. Étude nationale nutrition santé ENNS, 2006: Situation nutritionnelle en France en 2006 selon les indicateurs d'objectif et les repères du Programme National Nutrition Santé (PNNS). Saint-Maurice: Institut de Veille Sanitaire (InVS); 2007. Maladies chroniques et traumatismes.

7. Engeland A, Bjorge T, Tverdal A, Sogaard AJ: Obesity in adolescence and adulthood and the risk of adult mortality. Epidemiology 2004, 15:79-85.

8. Freedman DS, Khan LK, Dietz WH, Srinivasan SR, Berenson GS: Relationship of childhood obesity to coronary heart disease risk factors in adulthood: the Bogalusa Heart Study. Pediatrics 2001, 108:712-718.

9. Koplan JP, Liverman CT, Kraak VI: Extent and Consequences of Childhood Obesity. In Preventing Childhood Obesity: Health in the Balance. Edited by nstitute of medicine of the national academies. Washington, DC: The national academies press; 2005:54-78. 
10. Wang LY, Chyen D, Lee $S$, Lowry R: The association between body mass index in adolescence and obesity in adulthood. J Adolesc Health 2008 , 42:512-518.

11. Kumanyika SK, Obarzanek E, Stettler N, Bell R, Field AE, Fortmann SP, et al: Population-based prevention of obesity: the need for comprehensive promotion of healthful eating, physical activity, and energy balance: a scientific statement from American Heart Association Council on Epidemiology and Prevention, Interdisciplinary Committee for Prevention (formerly the expert panel on population and prevention science). Circulation 2008, 118:428-464.

12. Williams J, Wake M, Hesketh K, Maher E, Waters E: Health-related quality of life of overweight and obese children. JAMA 2005, 293:70-76.

13. Evans DR: Enhancing quality of life in the population at large. Soc Indic Res 1994, 33:47-88.

14. Mackeigan LD, Pathak DS: Overview of health-related quality-of-life measures. Am J Hosp Pharm 1992, 49:2236-2245.

15. World Health Organisation: Health promotion glossary. In Edited by World Health Organisation. WHO/HPR/HEP/98.1. Switzerland: Geneva; 1998:1-36.

16. Story MT, Neumark-Stzainer DR, Sherwood NE, Holt K, Sofka D, Trowbridge $F L$, et al: Management of child and adolescent obesity: attitudes, barriers, skills, and training needs among health care professionals. Pediatrics 2002, 110:210-214.

17. Story M, Nanney MS, Schwartz MB: Schools and obesity prevention: creating school environments and policies to promote healthy eating and physical activity. Milbank Q 2009, 87:71-100.

18. Bergman MM, Scott J: Young adolescents' wellbeing and health-risk behaviours: gender and socio-economic differences. J Adolesc 2001, 24:183-197.

19. Bisegger C, Cloetta B, Von RU, Abel T, Ravens-Sieberer U: Health-related quality of life: gender differences in childhood and adolescence. Soz Praventivmed 2005, 50:281-291.

20. Michel G, Bisegger C, Fuhr DC, Abel T: Age and gender differences in health-related quality of life of children and adolescents in Europe: a multilevel analysis. Qual Life Res 2009, 18:1147-1157.

21. Fallon EM, Tanofsky-Kraff M, Norman AC, McDuffie JR, Taylor ED, Cohen ML, et al: Health-related quality of life in overweight and nonoverweight black and white adolescents. J Pediatr 2005, 147:443-450.

22. Swallen KC, Reither EN, Haas SA, Meier AM: Overweight, obesity, and health-related quality of life among adolescents: the National Longitudinal Study of Adolescent Health. Pediatrics 2005, 115:340-347.

23. Pinhas-Hamiel O, Singer S, Pilpel N, Fradkin A, Modan D, Reichman B: Health-related quality of life among children and adolescents: associations with obesity. Int J Obes (Lond) 2006, 30:267-272.

24. de Beer M, Hofsteenge GH, Koot HM, Hirasing RA, de Waal HA D-v, Gemke $\mathrm{RJ}$ : Health-related-quality-of-life in obese adolescents is decreased and inversely related to BMI. Acta Paediatr 2007, 96:710-714.

25. Tsiros MD, Olds T, Buckley JD, Grimshaw P, Brennan L, Walkley J, et al: Health-related quality of life in obese children and adolescents. Int J Obes (Lond) 2009, 33:387-400.

26. Keating $C L$, Moodie ML, Swinburn BA: The health-related quality of life of overweight and obese adolescents-a study measuring body mass index and adolescent-reported perceptions. Int J Pediatr Obes 2011, 6:434-441.

27. Song AY, Rubin JP, Thomas V, Dudas JR, Marra KG, Fernstrom MH: Body image and quality of life in post massive weight loss body contouring patients. Obesity (Silver Spring) 2006, 14:1626-1636

28. Briançon S, Bonsergent E, Agrinier N, Tessier S, Legrand K, Lecomte E, et al: PRALIMAP: study protocol for a high school-based, factorial cluster randomised interventional trial of three overweight and obesity prevention strategies. Trials 2010, 11:119.

29. INSEE (Institut National de la Statistique et des Études Économiques), DARES (Ministère des affaires sociales, du travail et de la solidarité): Nomenclature des professions et catégories socioprofessionnelles des emplois salariés d'entreprise PCS - ESE 2003. http://www.insee.fr/fr/methodes/default.asp? page $=$ nomenclatures/pcsese/pcsese2003/pcsese2003.htm (accessed in 2012)

30. Cole TJ, Flegal KM, Nicholls D, Jackson AA: Body mass index cut offs to define thinness in children and adolescents: international survey. BMJ 2007, 335:194.
31. Parkerson GR Jr, Broadhead WE, Tse CK: The Duke Health Profile. A 17item measure of health and dysfunction. Med Care 1990, 28:1056-1072.

32. Vo TX, Guillemin F, Deschamps JP: Psychometric properties of the DUKE Health Profile-adolescent version (DHP-A): a generic instrument for adolescents. Qual Life Res 2005, 14:2229-2234

33. Guillemin F, Paul-Dauphin A, Virion JM, Bouchet C, Briancon S: The DUKE health profile: a generic instrument to measure the quality of life tied to health. Sante Publique 1997, 9:35-44.

34. World Health Organization: In Official Records of the World Health Organization. 2nd edition. Edited by World Health Organization. New-York: 1946.

35. Goldstein H: Multilevel statistical models. 4th edition. Hoboken: Wiley; 2011.

36. Cohane $\mathrm{GH}$, Pope HG Jr: Body image in boys: a review of the literature. Int J Eat Disord 2001, 29:373-379.

37. Duncan MJ, Al Nakeeb Y, Nevill AM, Jones MV: Body dissatisfaction, body fat and physical activity in British children. Int J Pediatr Obes 2006, 1:89-95.

38. Bergström E, Stenlud D, Svedjehäll B: Assessment of body perception among Swedish adolescents and young adults. J Adolesc Health 2000, 26:43-57.

39. ter Bogt TF, van Dorsselaer SA, Monshouwer K, Verdurmen JE, Engels RC Vollebergh WA: Body mass index and body weight perception as risk factors for internalizing and externalizing problem behavior among adolescents. J Adolesc Health 2006, 39:27-34.

40. Unterhalter G, Farell S, Mohr C: Selective memory bias for words reflecting sexe specific body image concerns. Eat Behav 2007, 8:382-389.

41. Lawler M, Nixon E: Body dissatisfaction among adolescents boys and girls: the effect of body mass, peer appearance culture and internationalization of appearance ideals. J Youth Adolesc 2011, 40:59-71.

42. El Ansari W, Vodder Clausen S, Mabhala A, Stock C: How do i look? Body image perceptions among university students from England ans Denmark. Int J Environ Res Public Health 2010, 7:583-595.

43. Pearce MJ, Boergers J, Prinstein MJ: Adolescent obesity, overt and relational peer victimization, and romantic relationships. Obes Res 2002, 10:386-393.

44. Bradford-Hill A: The environment and disease: assocation or causation? Proc R Soc Med 1965, 58:295-300.

45. Zwiauer K, Caroli M, Malecka-Tendera E, Poskitt E: Clinical features, adverse effects and outcome. In Child and adolescent obesity. Causes and consequences. Prevention and mangement. Edited by Burniat W, Cole TJ, Lissau I, Poskitt E. Cambridge: Cambridge University Press; 2002:1-416.

\section{doi:10.1186/1471-2458-12-997}

Cite this article as: Bonsergent et al:: Effect of gender on the association between weight status and health-related quality of life in adolescents. BMC Public Health 2012 12:997.

\section{Submit your next manuscript to BioMed Central and take full advantage of:}

- Convenient online submission

- Thorough peer review

- No space constraints or color figure charges

- Immediate publication on acceptance

- Inclusion in PubMed, CAS, Scopus and Google Scholar

- Research which is freely available for redistribution 